OPEN ACCESS

Edited by:

Kequan $\mathrm{Yu}$,

Tongji University, China

Reviewed by:

Junqi Huang,

Hefei University of Technology, China Kun Dong,

Ocean University of China, China

*Correspondence: Bin Ding

dingb0577@163.com

Wan-Yang Gao

wanyanggao@sjtu.edu.cn

Specialty section:

This article was submitted to

Structural Materials,

a section of the journal

Frontiers in Materials

Received: 23 June 2021

Accepted: 06 August 2021

Published: 23 September 2021

Citation:

Ouyang $L-J$

Wei $X$-X Ding $B$ and

Gao W-Y (2021) Effective Strain of BFRP for Confined Heat-Damaged

Concrete Cylinders.

Front. Mater. 8:729781.

doi: 10.3389/fmats.2021.729781

\section{Effective Strain of BFRP for Confined Heat-Damaged Concrete Cylinders}

\author{
Li-Jun Ouyang ${ }^{1}$, Xiao-Xiao Wei ${ }^{1}$, Bin Ding ${ }^{2 *}$ and Wan-Yang Gao ${ }^{3,4 *}$ \\ ${ }^{1}$ School of Environment and Architecture, University of Shanghai for Science and Technology, Shanghai, China, ${ }^{2}$ Department of \\ Civil Engineering, Wenzhou Polytechnic, Wenzhou, China, ${ }^{3}$ State Key Laboratory of Ocean Engineering, Shanghai Jiao Tong \\ University, Shanghai, China, ${ }^{4}$ Shanghai Key Laboratory for Digital Maintenance of Buildings and Infrastructure, School of Naval \\ Architecture, Ocean and Civil Engineering, Shanghai Jiao Tong University, Shanghai, China
}

It is widely accepted that concrete columns confined with fiber-reinforced polymer (FRP) jackets exhibit significant increases in strength and ductility with reference to the unconfined case. Existing experimental studies have indicated that the hoop rupture strains measured in the FRP jackets are significantly lower than the material strain capacity determined by the flat coupon tensile tests. An FRP efficiency factor is then usually used to define the ratio of the average hoop rupture strain to the material strain capacity of the FRP jackets, which governs the lateral FRP confinement as well as the peak strength and ultimate strain of the FRP-confined concrete under axial compression. FRP jackets are also expected to be a promising solution to repair damaged RC columns after fire exposure. However, there is lacking research on the behavior of FRP-confined fire or heat-damaged concrete columns. In particular, the FRP efficiency factor of FRP-confined fire or heatdamaged concrete columns has not yet been established. The study presents the results of an experimental study aimed to investigate the effects of the historical high temperature and the layer of basalt FRP (BFRP) jackets on the efficiency factor of BFRP for the confined heat-damaged concrete cylinders. A sum of 51 standard concrete cylinders is prepared and tested under axial compression. The parameters varied between tests are the historical high temperature $\left(200^{\circ} \mathrm{C}, 400^{\circ} \mathrm{C}, 600^{\circ} \mathrm{C}\right.$, or $\left.800^{\circ} \mathrm{C}\right)$ that is used to produce the heat damage of concrete cylinders and the number of layers of BFRP jackets $(2,3$, or 4). The test results have indicated that the efficiency factor of BFRP jackets increases with the historical high temperature but decreases slightly with the increase in the BFRP layers. A new temperature-dependent design equation for the BFRP efficiency factor of the confined heat-damaged concrete is proposed to consider the effects of the parameters mentioned above and can be used for practical design.

Keywords: basalt fiber-reinforced polymer, concrete cylinders, heat damage, efficiency factor, confined concrete, high temperature

\section{INTRODUCTION}

Fiber-reinforced polymer (FRP) composites have been widely used for the repair and strengthening of concrete columns. The use of FRP jackets can enhance the compressive strength and ductility of concrete columns. The success of FRP confinement is mainly related to the excellent properties of FRP composites, including high tensile strength, corrosion resistance, lightweight, and easy application (Jiang and Teng, 2013; Bai et al., 2021). Extensive research on FRP-confined 
concrete columns has led to a good understanding of the axial compressive behavior and the related concrete confinement models (Xiao and Wu, 2000; Ilki et al., 2008; Yu et al., 2010a; Yu et al., 2010b; De Luca et al., 2010; Dai et al., 2011; Ozbakkaloglu et al., 2013; Zhou et al., 2016; Bai et al., 2017; Lin and Teng, 2017; Ouyang et al., 2017; Wang et al., 2017; Zeng et al., 2017; Zeng et al., 2018; Guo et al., 2019; Zeng et al., 2020a; Zeng et al., 2020b; Zeng et al., 2020c; Lin and Teng, 2020; Yan et al., 2021; Zeng et al., 2021). It is well known that the failure mode of FRP-confined concrete cylinders is usually dominated by the tensile rupture of the FRP jackets in the hoop direction. The existing results have indicated that the FRP jackets usually exhibit tensile rupture failure with a strain level lower than the maximum tensile strain of the material measured by the flat coupon tests (Rousakis and Tepfers, 2004; Berthet et al., 2005; Lam et al., 2006; Jiang and Teng, 2007; Wang and Wu, 2008; Smith et al., 2010; Lim and Ozbakkaloglu, 2014; Jian and Ozbakkaloglu, 2015). In other words, the hoop rupture strain of FRP in FRP-confined concrete in the ultimate state is less than the maximum tensile strain obtained from the flat coupon tests. Therefore, some researchers have proposed FRP efficiency factors to describe the ratio of the hoop rupture strain of FRP jackets to the maximum tensile strain of the material. Also, several investigations have been conducted to propose design values of FRP efficiency factors [e.g. (Xiao and Wu, 2000; Lam and Teng, 2004; Rousakis and Tepfers, 2004; Smith et al., 2010; Chen et al., 2013; Wu and Jiang, 2013; Pham et al., 2015)]. It is found that the detailed values of the FRP efficiency factors exhibit large scatter, mainly due to the different design parameters considered in the existing experimental studies. For example, Lam and Teng (2004) reported that the FRP efficiency factor of nine CFRPconfined cylinders was only 0.581, while that of six GFRPconfined cylinders was 0.669. In addition, the American Concrete Institute (ACI) guidelines recommend using a constant value of 0.55 to determine the FRP efficiency factor of FRP-confined concrete for practical design purposes (ACI, 2008).

On the other hand, fire represents one of the most severe disasters that concrete structures may encounter during their service life. Concrete structures usually have good fire resistance, mainly due to the low thermal conductivity and noncombustibility of concrete, which provide good fire protection for the internal steel bars (Gao et al., 2014; Gao et al., 2016; Gao et al., 2017). Existing survey data show that concrete buildings rarely collapse in fires, and most of the fire-damaged reinforced concrete (RC) members can be repaired to restore their structural functions (Yaqub and Bailey, 2011; Yaqub et al., 2011; Yaqub et al., 2013; Al-Kamaki et al., 2015). The successful use of FRP jackets to strengthen RC columns indicates that they are also expected to be used to repair fire-damaged RC columns (Yaqub and Bailey, 2011; Yaqub et al., 2011; Yaqub et al., 2013; AlKamaki et al., 2015). However, limited research is available in the literature to study the confinement mechanism of FRP jackets on confined heat- or fire-damaged concrete (Bisby et al., 2011; Lenwari et al., 2016; Ouyang et al., 2021; Song et al., 2021). Bisby et al. (2011) evaluated the compressive strength and the related axial stressstrain responses of unconfined and
CFRP-confined concrete cylinders after exposure to various high temperatures (i.e., $300^{\circ} \mathrm{C}, 500^{\circ} \mathrm{C}$, and $686^{\circ} \mathrm{C}$ ). The test results showed that the heat-damaged concrete confined with a single CFRP jacket layer had a significant increase in the recorded axial strain at the time of failure compared with the unconfined concrete. The FRP efficiency factor of FRP-confined heat-damaged concrete is higher than that of the FRP-confined undamaged concrete. More recently, the authors conducted some axial compressive tests to investigate the confinement mechanism of BFRP-confined heat-damaged cylinders and prisms, and the authors also reported similar observations (Ouyang et al., 2021; Song et al., 2021). That is, in our tests, the BFRP jackets are more effective in enhancing the compressive strength of the heatdamaged concrete than that of the undamaged concrete. The FRP strengthening efficiency was more significant for the concrete cylinders or prisms with higher levels of heat-induced damage.

To further investigate the BFRP efficiency factor of the BFRPconfined heat-damaged concrete cylinders, this study presents the results of the axial compressive tests aiming to examine the effects of the heat-induced damage level of concrete and the number of BFRP jacket layers on the efficiency of BFRP jackets in the BFRPconfined heat-damaged concrete cylinders. Also, the failure modes and lateral strain distributions are examined and reported in detail. The test results show that the BFRP efficiency factor increases with the historical high temperature but slightly decreases with the increase of BFRP layers. In addition, a new temperature-dependent design equation for the BFRP efficiency factor of the confined heat-damaged concrete is proposed for practical design purposes.

\section{EXPERIMENTAL PROGRAM}

\section{Test Specimens}

In the study, 51 standard concrete cylinders with a diameter of $150 \mathrm{~mm}$ and a height of $300 \mathrm{~mm}$ were cast and tested under monotonic axial compression. The specimens were divided into three groups: one unheated case used as a control group, four cases of heat-damaged concrete without strengthening, and 12 cases of heat-damaged concrete with different layers of BFRP jackets. For each design case, three identical specimens were prepared. The variables of this study were the target temperatures $\left(20^{\circ} \mathrm{C}, 200^{\circ} \mathrm{C}, 400^{\circ} \mathrm{C}, 600^{\circ} \mathrm{C}\right.$, and $\left.800^{\circ} \mathrm{C}\right)$ and the number of layers of the BFRP jackets $(0,2,3$, and 4$)$. Each specimen is named by a label consisting of two letters ( $\mathrm{T}$ stands for the target temperature and $\mathrm{L}$ stands for the number of BFRP layers), followed by a number to distinguish nominally identical specimens. For instance, "T400-L2-1" denotes the first specimen of three duplicates that was heat-damaged after exposure to $400^{\circ} \mathrm{C}$ and then confined with two layers of BFRP jackets.

\section{Material Properties}

All the specimens were cast with the same concrete mix design. The concrete mix included sand, crushed granitic rocks, ordinary Portland cement (OPC), and water. River sand was used as the fine aggregate, and crushed granitic rocks with a maximum size of 
TABLE 1 | Properties of BFRP sheets.

\begin{tabular}{|c|c|c|c|c|c|}
\hline Type & Specimen & $t(\mathrm{~mm})$ & $\varepsilon_{\text {frp }}$ & $\mathbf{f}_{\text {frp }}(\mathbf{M P a})$ & $\mathbf{E}_{\text {frp }}(\mathbf{G P a})$ \\
\hline \multirow[t]{4}{*}{ Flat coupon test } & 1 & 0.121 & 0.0219 & $2,368.49$ & 108.15 \\
\hline & 2 & 0.242 & 0.0218 & $2,317.99$ & 106.33 \\
\hline & 3 & 0.363 & 0.0217 & $2,408.27$ & 110.98 \\
\hline & 4 & 0.484 & 0.0221 & $2,408.27$ & 105.14 \\
\hline Data supplied by the manufacturer & - & 0.121 & 0.0218 & 2,303 & 105 \\
\hline
\end{tabular}

$10 \mathrm{~mm}$ were used as the coarse aggregate. The mixing proportion of 1 cubic meter of concrete consisted of $438 \mathrm{~kg}$ cement, $704 \mathrm{~kg}$ fine aggregate, $1,103 \mathrm{~kg}$ coarse aggregate, and $206 \mathrm{~kg}$ water. The compressive strength and elastic modulus of concrete were determined to be $45.1 \mathrm{MPa}$ and $21.9 \mathrm{GPa}$, respectively. The basalt fibers used in the study were in the form of continuous unidirectional fabric sheets with a nominal thickness of $0.121 \mathrm{~mm}$ and a width of $300 \mathrm{~mm}$. The tensile strength and elastic modulus of the BFRP jackets were obtained according to the flat coupon tests recommended by the ASTM D3039 standard (ASTM, 2017). Table 1 lists the test results and the specified mechanical properties of BFRP sheets provided by the manufacturer.

\section{Heating Regime}

Four representative high temperatures (i.e., $200^{\circ} \mathrm{C}, 400^{\circ} \mathrm{C}, 600^{\circ} \mathrm{C}$, and $800^{\circ} \mathrm{C}$ ) were used in this study to induce the light (after exposure to $200^{\circ} \mathrm{C}$ ), moderate (after exposure to $400^{\circ} \mathrm{C}$ or $600^{\circ} \mathrm{C}$ ), and severe (after exposure to $800^{\circ} \mathrm{C}$ ) damage of concrete. Three standard concrete cylinders (unheated) were tested at $20^{\circ} \mathrm{C}$ as a control group. Prior to heat exposure, the remaining 48 concrete cylinders were oven-dried at $105^{\circ} \mathrm{C}$ for $24 \mathrm{~h}$ to reduce the water content of the concrete. It is well recognized that the high water content in concrete may cause explosive spalling of concrete during heating (Gao et al., 2013; Yang et al., 2019), and RC columns that have been serviced for many years generally exhibit much lower water content than fresh concrete. Therefore, the purpose of pre-drying treatment is to reduce the moisture content of fresh concrete so that the concrete reaches a relatively actual moisture content like that during service. The concrete cylinders were exposed to a high temperature of $200^{\circ} \mathrm{C}, 400^{\circ} \mathrm{C}, 600^{\circ} \mathrm{C}$, or $800^{\circ} \mathrm{C}$ in an electric furnace. A heating rate of $5^{\circ} \mathrm{C} / \mathrm{min}$ was set for the furnace temperature, which was monitored by a thermocouple placed in the chamber. After the high temperature was obtained, it was maintained for $2.5 \mathrm{~h}$ to endure that the entire cross-section of the concrete cylinder achieved an almost uniform high temperature. Such a heating period was determined by numerical analysis of heat transfer according to the finite element model proposed by the authors (Gao et al., 2013; Gao et al., 2015; Gao et al., 2018). After finishing the heating process, the door of the furnace was opened, and the concrete cylinders were left in the chamber to be cooled down naturally. Post-heating inspection of all the cylinders was carefully carried out. It was obvious that as the high temperature increased, some slight micro-cracks appeared on the surfaces of the concrete cylinders, and no severe explosive spalling occurred. Only some slight concrete spalling was observed for the cylinders after exposure to $800^{\circ} \mathrm{C}$. The reason may be due to the positive impact on the concrete cylinders during the early preheating process.

\section{Repair Process of Heat-Damaged Concrete Cylinders}

Before applying the BFRP jackets, an epoxy mortar (Sikadur $^{\circledR}$-31 CF Normal) was first applied to repair the heat-damaged concrete cylinders to fill the concrete cracks caused by local concrete spalling. After that, the repaired specimens were cured in a laboratory environment for 7 days to make the epoxy mortar reach a sufficient hardening state according to the recommendations provided by the design specification (GB, 2006). Then, the concrete surfaces of the cylinders were burnished with abrasive paper, and acetone was used to wipe the surfaces of the concrete cylinders. Any dust or pollutants were removed by compressed air. The epoxy adhesive used to bond the BFRP jackets was a twopart resin consisting of an epoxy (Part A) and a hardener (Part B), and the mixing ratio was $3: 2$ by volume. The tensile strength and elastic modulus of the epoxy resin provided by the material manufacturer are $40 \mathrm{MPa}$ and $2.5 \mathrm{GPa}$, respectively. A thin layer of two-part epoxy resin was applied on the cleaned concrete surface as a primer, then the BFRP sheets were wrapped along the hoop direction, and another layer of epoxy resin was brushed on the surface of the BFRP sheets and served as a polymer matrix. The BFRP sheets were continuously wrapped around the heat-damaged cylinders with the primary fibers orienting in the hoop direction, and there were additional 150-mm-length BFRP sheets in the overlapping zone. Two additional $20 \mathrm{~mm}$ BFRP jackets were used at both ends of the column to prevent possible premature failure near the two ends.

The mechanical properties of BFRP sheets were measured by tensile coupon tests following the ACI testing code (ASTM, 2017). Table 1 lists the detailed values of the tensile strength and elastic modulus of the BFRP sheets obtained from the flat coupon tests, in which the mechanical properties supplied by the material manufacturer were provided as a reference. The BFRPconfined heat-damaged specimens were cured under laboratory conditions for 7 days to ensure that the epoxy adhesive was fully cured according to the provisions supplied by the ACI design code (ACI, 2008). The prepared specimens were further placed in the laboratory at least 2 weeks before the axial compression tests. 

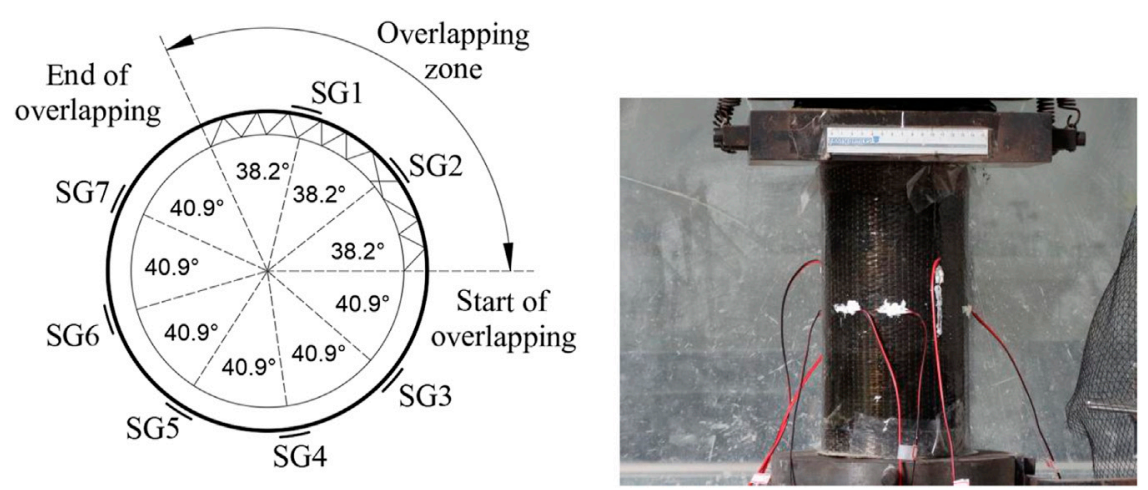

FIGURE 1 | Arrangement of strain gauges.

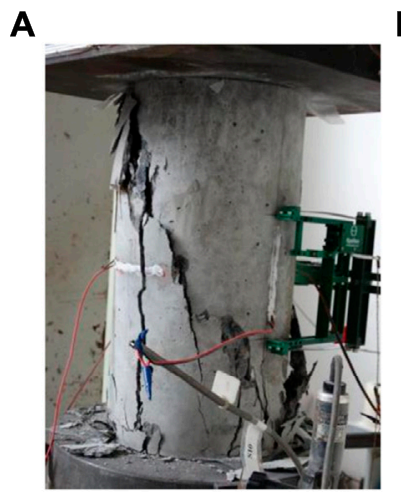

$20^{\circ} \mathrm{C}$

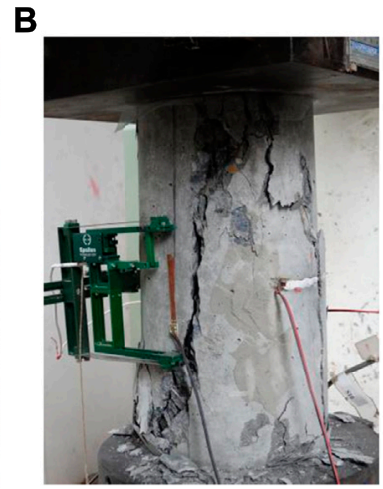

$200^{\circ} \mathrm{C}$

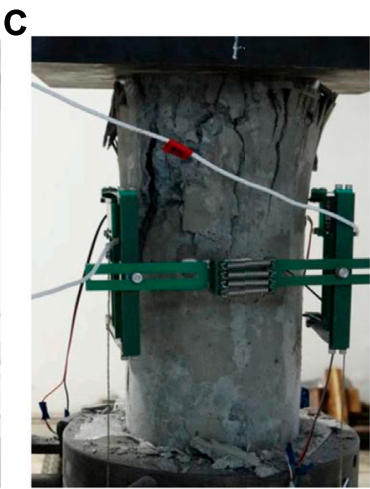

$400^{\circ} \mathrm{C}$
D

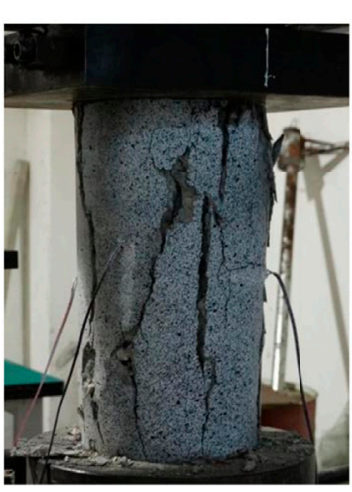

$600^{\circ} \mathrm{C}$
E

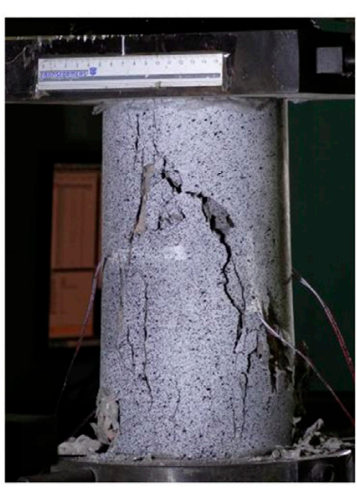

$800^{\circ} \mathrm{C}$

FIGURE 2 | Failure modes of unconfined heat-damaged concrete cylinders. (A) $20^{\circ} \mathrm{C}$, (B) $200^{\circ} \mathrm{C}$, (C) $400^{\circ} \mathrm{C}$, (D) $600^{\circ} \mathrm{C}$, (E) $800^{\circ} \mathrm{C}$.

\section{Test Setup and Testing Procedure}

The specimens were tested under axial compression using a $2,000 \mathrm{kN}$ loading system. A displacement-controlled method was adopted for the axial compression tests, in which the specimens were loaded at a constant displacement rate of $0.2 \mathrm{~mm} / \mathrm{min}$. Before testing, each column was capped with dental plaster at its top and bottom to achieve parallel surfaces and help the load be distributed uniformly. Two clip-on extensometers with a gauge length of $100 \mathrm{~mm}$ were placed at the middle height of each specimen to measure the axial deformations. Lateral strain responses of BFRP jackets were sufficiently measured by seven strain gauges with a $10-\mathrm{mm}$ gauge length, which were distributed at the mid-height of the cylinder along the hoop direction, as shown in Figure 1. Two strain gauges were located in the 150 -mm overlapping zone, and the remaining five were evenly distributed in the non-overlapping 


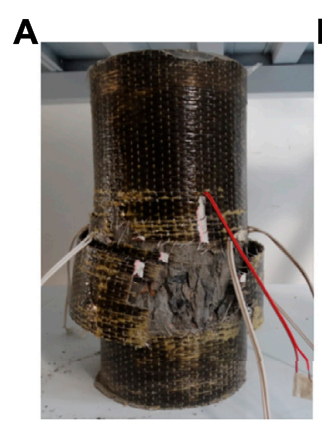

$200^{\circ} \mathrm{C}$

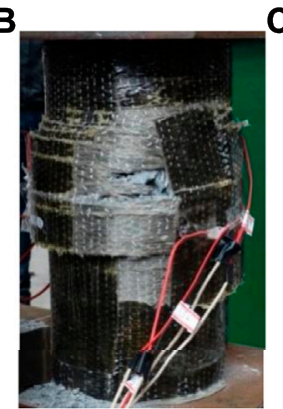

$400^{\circ} \mathrm{C}$

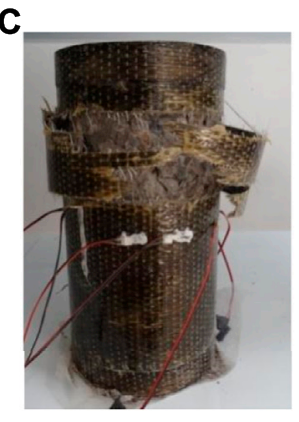

$600^{\circ} \mathrm{C}$

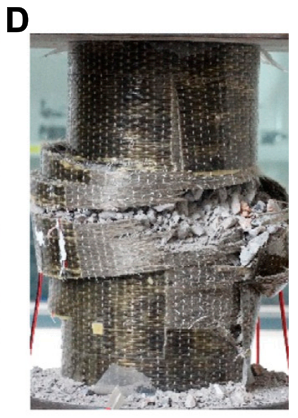

$800^{\circ} \mathrm{C}$

FIGURE 3 | Failure modes of BFRP-confined heat-damaged concrete cylinders. (A) $200^{\circ} \mathrm{C}$, (B) $400^{\circ} \mathrm{C}$, (C) $600^{\circ} \mathrm{C}$, (D) $800^{\circ} \mathrm{C}$.

zone. All the test data (i.e., load force, displacement, and strain measurements) were monitored and recorded by an automatic data acquisition system.

\section{FAILURE MODES}

Figure 2 shows the failure modes of the unconfined heatdamaged concrete cylinders after exposure to various high temperatures. All the failures of the unconfined cylinders were caused by the concrete crushing. For the reference (unheated) specimens tested at $20^{\circ} \mathrm{C}$, the failure was sudden and brittle with relatively small deformation capacity. Compared with the reference specimens, the failure process of the heat-damaged concrete cylinders was more gradual and continuous. This was because the heat-damaged concrete became more ductile after high temperature exposure. As the high temperatures increased, the colors of the heat-damaged concrete cylinders were changed from grey to whitish-grey, and some micro-cracks were observed on the surface of the specimen. However, several concrete cracks with some fragments of concrete crushed were observed for the specimens after heating to high temperatures of $600^{\circ} \mathrm{C}$ and $800^{\circ} \mathrm{C}$. It is worth mentioning that the failure mode of the concrete cylinders after heating to $200^{\circ} \mathrm{C}$ is similar to that of the unheated specimens (Figure $\mathbf{2 A}$ ), which is mainly due to the fact that the high temperature level of $200^{\circ} \mathrm{C}$ will not significantly reduce the mechanical properties of concrete.

Figure 3 depicts the failure modes of heat-damaged concrete cylinders confined by the BFRP jackets. The failure of each BFRP-confined heat-damaged concrete cylinder occurred due to the tensile rupture of the fiber jackets in the mid-height zone of the specimen. During the loading process, cracking sounds were observed prior to the failure, indicating that the confinement of the BFRP jackets was activated. When approaching the peak load, visible wrinkles caused by lateral dilation were witnessed followed by a sudden explosive failure of the fibers accompanying the concrete crushing. It was noted that the rupture of the BFRP jackets occurred in the middle height zone of each concrete cylinder rather than at the top or bottom zone, which was mainly due to the additional confinement provided by the use of $20-\mathrm{mm}$ BFRP strips in both end zones. In addition, the concrete crushing became more significant with the increase in the number of BFRP jacket layers. The rupture failure of heat-damaged concrete cylinders confined by the BFRP jackets proved that the overlap of $150 \mathrm{~mm}$ was sufficient to provide adequate confinement and prevent undesirable failure caused by the debonding of the BFRP jackets in the overlapping zone.

\section{RESULTS AND DISCUSSION}

The main test results are summarized in Tables 2 and 3. Table 2 shows the compressive strength and the corresponding axial strain of the unconfined concrete $\left(f_{c o}\right.$ and $\left.\varepsilon_{o}\right)$, the compressive strength and the ultimate axial strain of the BFRP-confined heat-damaged concrete $\left(f_{c c}\right.$ and $\left.\varepsilon_{c u}\right)$, and the maximum, minimum, and average hoop strains $\left(\varepsilon_{h, \text { max }}, \varepsilon_{h, \text { min }}\right.$, $\left.\varepsilon_{\text {h,ave }}\right)$ recorded by the seven strain gauges installed on the FRP jackets in the ultimate state. In this table, $k_{\varepsilon 1}$ is defined as the ratio of the average hoop rupture strain (i.e., $\varepsilon_{h, a v e}$ ) to the maximum hoop strain (i.e., $\varepsilon_{h, \text { max }}$ ), while $k_{\varepsilon 2}$ is determined as the ratio of $\varepsilon_{h, \text { max }} / \varepsilon_{\text {frp }}$. The efficiency factor $\left(k_{\varepsilon}\right)$ is the product of the above two ratios (i.e., $k_{\varepsilon}=k_{\varepsilon 1} \times k_{\varepsilon 2}$ ). Table 3 provides the hoop strains under the ultimate conditions recorded by the strain gauges. It is worth noting that the strain responses of T600-L3-2 and T600L4-1 were not recorded during the loading tests due to instrument error.

\section{Strain Distribution in the Overlapping Zone}

It is well known that the lateral confinement provided by the FRP jackets is proportional to the FRP hoop rupture strain as follows:

$$
f_{l}=\frac{2 n E_{f r p} t_{f r p} \varepsilon_{\text {hoop }}}{D}
$$

where $f_{l}$ is the confinement pressure provided by the FRP jackets, $n$ is the number of the FRP jacket layers, $E_{f r p}$ is the elastic modulus of FRP jackets obtained from the flat coupon tests, $t_{f r p}$ is the nominal thickness of the FRP jackets, $\varepsilon_{\text {hoop }}$ is the average 
TABLE 2 | Results of the compressive tests.

\begin{tabular}{|c|c|c|c|c|c|c|c|c|c|c|}
\hline Specimen & $\begin{array}{c}f_{c o} \\
(M P a)\end{array}$ & $\begin{array}{l}\varepsilon_{0} \\
(\varepsilon)\end{array}$ & $\begin{array}{c}\boldsymbol{f}_{c c} \\
(M P a)\end{array}$ & $\begin{array}{l}\varepsilon_{\mathrm{cu}} \\
(\varepsilon)\end{array}$ & $\begin{array}{c}\varepsilon_{\mathrm{h}, \max } \\
(\varepsilon)\end{array}$ & $\begin{array}{c}\varepsilon_{\mathrm{h}, \min } \\
(\varepsilon)\end{array}$ & $\begin{array}{c}\mathcal{E}_{\mathrm{h}, \text { ave }} \\
(\varepsilon)\end{array}$ & $\mathbf{k}_{\varepsilon 1}$ & $\mathbf{k}_{\varepsilon 2}$ & $\mathbf{k}_{\varepsilon}$ \\
\hline T200-L2-1 & 41.81 & 0.003 & 59.32 & 0.011 & 0.019 & 0.011 & 0.016 & 0.812 & 0.893 & 0.726 \\
\hline T200-L2-2 & 41.81 & 0.003 & 69.35 & 0.011 & 0.019 & 0.010 & 0.016 & 0.819 & 0.887 & 0.727 \\
\hline T200-L2-3 & 41.81 & 0.003 & 67.28 & 0.012 & 0.019 & 0.011 & 0.016 & 0.820 & 0.886 & 0.726 \\
\hline T200-L3-1 & 41.81 & 0.003 & 78.11 & / & 0.019 & 0.012 & 0.016 & 0.822 & 0.886 & 0.728 \\
\hline T200-L3-2 & 41.81 & 0.003 & 74.96 & 0.015 & 0.018 & 0.012 & 0.016 & 0.865 & 0.841 & 0.728 \\
\hline T200-L3-3 & 41.81 & 0.003 & 80.16 & 0.014 & 0.019 & 0.012 & 0.016 & 0.823 & 0.883 & 0.727 \\
\hline T200-L4-1 & 41.81 & 0.003 & 107.95 & 0.017 & 0.019 & 0.013 & 0.016 & 0.815 & 0.893 & 0.728 \\
\hline T200-L4-2 & 41.81 & 0.003 & 100.75 & 0.017 & 0.018 & 0.013 & 0.016 & 0.866 & 0.840 & 0.727 \\
\hline T200-L4-3 & 41.81 & 0.003 & 93.54 & 0.018 & 0.018 & 0.013 & 0.016 & 0.906 & 0.804 & 0.729 \\
\hline T400-L2-1 & 35.57 & 0.004 & 61.43 & 0.013 & 0.020 & 0.011 & 0.016 & 0.824 & 0.902 & 0.743 \\
\hline T400-L2-2 & 35.57 & 0.004 & 67.58 & 0.013 & 0.020 & 0.011 & 0.016 & 0.827 & 0.896 & 0.741 \\
\hline T400-L2-3 & 35.57 & 0.004 & 64.96 & 0.013 & 0.020 & 0.011 & 0.016 & 0.830 & 0.896 & 0.743 \\
\hline T400-L3-1 & 35.57 & 0.004 & 78.75 & 0.015 & 0.019 & 0.012 & 0.016 & 0.829 & 0.891 & 0.739 \\
\hline T400-L3-2 & 35.57 & 0.004 & 77.19 & 0.016 & 0.019 & 0.012 & 0.016 & 0.829 & 0.893 & 0.740 \\
\hline T400-L3-3 & 35.57 & 0.004 & 78.09 & 0.016 & 0.019 & 0.012 & 0.016 & 0.833 & 0.890 & 0.742 \\
\hline T400-L4-1 & 35.57 & 0.004 & 106.94 & 0.020 & 0.018 & 0.013 & 0.016 & 0.870 & 0.840 & 0.730 \\
\hline T400-L4-2 & 35.57 & 0.004 & 99.53 & 0.020 & 0.019 & 0.013 & 0.016 & 0.825 & 0.886 & 0.731 \\
\hline T400-L4-3 & 35.57 & 0.004 & 101.17 & 0.020 & 0.019 & 0.013 & 0.016 & 0.829 & 0.885 & 0.734 \\
\hline T600-L2-1 & 17.87 & 0.005 & 56.79 & 0.017 & 0.021 & 0.011 & 0.017 & 0.833 & 0.949 & 0.791 \\
\hline T600-L2-2 & 17.87 & 0.005 & 59.37 & 0.016 & 0.019 & 0.011 & 0.018 & 0.944 & 0.853 & 0.805 \\
\hline T600-L2-3 & 17.87 & 0.005 & 62.99 & / & 0.021 & 0.012 & 0.017 & 0.841 & 0.947 & 0.797 \\
\hline T600-L3-1 & 17.87 & 0.005 & 71.23 & 0.019 & 0.021 & 0.013 & 0.017 & 0.841 & 0.941 & 0.791 \\
\hline T600-L3-2 & 17.87 & 0.005 & 73.89 & 0.020 & / & / & / & / & / & / \\
\hline T600-L3-3 & 17.87 & 0.005 & 75.77 & 0.021 & 0.021 & 0.013 & 0.017 & 0.842 & 0.940 & 0.792 \\
\hline T600-L4-1 & 17.87 & 0.005 & 94.87 & 0.025 & / & / & / & / & / & / \\
\hline T600-L4-2 & 17.87 & 0.005 & 91.66 & 0.024 & 0.020 & 0.014 & 0.017 & 0.848 & 0.929 & 0.788 \\
\hline T600-L4-3 & 17.87 & 0.005 & 98.08 & / & 0.019 & 0.014 & 0.017 & 0.892 & 0.884 & 0.788 \\
\hline T800-L2-1 & 16.42 & 0.008 & 55.56 & 0.020 & 0.019 & 0.011 & 0.018 & 0.934 & 0.864 & 0.807 \\
\hline T800-L2-2 & 16.42 & 0.008 & 58.19 & 0.018 & 0.021 & 0.011 & 0.018 & 0.851 & 0.954 & 0.811 \\
\hline T800-L2-3 & 16.42 & 0.008 & 58.70 & 0.020 & 0.021 & 0.011 & 0.018 & 0.854 & 0.950 & 0.811 \\
\hline T800-L3-1 & 16.42 & 0.008 & 71.62 & 0.022 & 0.021 & 0.013 & 0.018 & 0.852 & 0.942 & 0.803 \\
\hline T800-L3-2 & 16.42 & 0.008 & 70.18 & 0.022 & 0.019 & 0.013 & 0.017 & 0.896 & 0.892 & 0.799 \\
\hline T800-L3-3 & 16.42 & 0.008 & 73.04 & 0.024 & 0.020 & 0.013 & 0.017 & 0.850 & 0.940 & 0.798 \\
\hline T800-L4-1 & 16.42 & 0.008 & 93.65 & 0.029 & 0.020 & 0.014 & 0.017 & 0.842 & 0.935 & 0.787 \\
\hline T800-L4-2 & 16.42 & 0.008 & 95.10 & 0.027 & 0.020 & 0.014 & 0.017 & 0.848 & 0.935 & 0.793 \\
\hline T800-L4-3 & 16.42 & 0.008 & 90.94 & 0.027 & 0.019 & 0.014 & 0.017 & 0.928 & 0.855 & 0.793 \\
\hline
\end{tabular}

Note: ""-Unreliable data.

hoop strain in the overlapping zone, $D$ is the diameter of the confined concrete core. Since the tensile force of the FRP jackets can be regarded as a constant, the difference in the recorded strain responses between the overlapping zone and the nonoverlapping zone can be determined by the following theoretical strain ratio:

$$
\frac{\varepsilon_{\text {overlap }}}{\varepsilon_{\text {non-overlap }}}=\frac{n_{\text {non-overlap }}}{n_{\text {overlap }}}
$$

where $\varepsilon_{\text {overlap }}$ is the average hoop strain of the overlapping zone, $\varepsilon_{\text {non-overlap }}$ is the average hoop strain of the non-overlapping zone (i.e., $\varepsilon_{\text {h,ave }}$ in Table 2 ), $n_{\text {overlap }}$ is the number of FRP layers in the overlapping zone, and $n_{\text {non-overlap }}$ is the number of FRP layers in the non-overlapping zone. To further examine the strain distribution of BFRP jackets in the BFRP-confined heatdamaged concrete, Figure 4 shows the details of the measurements recorded by the seven strain gauges for the tested specimens after exposure to $200^{\circ} \mathrm{C}$ and $800^{\circ} \mathrm{C}$. It is seen that the minimum strain $\varepsilon_{\min }$ is obtained in the overlapping zone, which occurs at the strain gauge SG1 near the end of the jackets. Comparatively speaking, the lateral strain measured by the strain gauge SG2 in the overlapping zone is much closer to that measured at the strain gauge SG3 in the non-overlapping zone. In other words, the strain values measured by the two strain gauges in the overlapping zone are different, and the difference between them increases with the distance from the edge of the BFRP jackets. This observation was also reported by Lam and Teng (Lam and Teng, 2004).

Table 4 shows the strain difference recorded by the two strain gauges in the overlapping zone. It can be seen from the table that when the same BFRP jacket layer is used, the ratio of the measured lateral strain of $\varepsilon_{h, S G 1}$ to $\varepsilon_{h, a v e}$ is close to the theoretical ratio (i.e., $n_{\text {overlap }} / n_{\text {non-overlap }}$ ), while the ratio of the hoop strain of $\varepsilon_{h, S G 2}$ to $\varepsilon_{h \text {,ave }}$ is usually higher than the theoretical ratio. The results further indicate that in the overlapping zone, the confinement efficiency of the BFRP jackets increases with the increase of the distance from the end edge of the FRP jackets. This is because when the concrete 
TABLE 3 | Hoop strain responses at the ultimate condition.

\begin{tabular}{|c|c|c|c|c|c|c|c|c|c|c|}
\hline \multirow[t]{2}{*}{ Specimen } & \multirow[t]{2}{*}{ Layer } & \multicolumn{3}{|c|}{ Overlapping zone } & \multicolumn{6}{|c|}{ Non-overlapping zone } \\
\hline & & SG1 & SG2 & $\varepsilon_{\text {ave,ovl }}$ & SG3 & SG4 & SG5 & SG6 & SG7 & $\varepsilon_{\text {ave,non }}$ \\
\hline T200-L2-1 & 2 & 0.0106 & 0.0133 & 0.0119 & 0.0154 & 0.0133 & 0.0195 & 0.0163 & 0.0147 & 0.0158 \\
\hline T200-L2-2 & 2 & 0.0105 & 0.0140 & 0.0122 & 0.0139 & 0.0193 & 0.0151 & 0.0179 & 0.0130 & 0.0159 \\
\hline T200-L2-3 & 2 & 0.0105 & 0.0132 & 0.0119 & 0.0139 & 0.0141 & 0.0146 & 0.0173 & 0.0193 & 0.0158 \\
\hline T200-L3-1 & 3 & 0.0120 & 0.0140 & 0.0130 & 0.0157 & 0.0193 & 0.0165 & 0.0143 & 0.0135 & 0.0159 \\
\hline T200-L3-2 & 3 & 0.0117 & 0.0140 & 0.0129 & 0.0137 & 0.0135 & 0.0164 & 0.0183 & 0.0175 & 0.0159 \\
\hline T200-L3-3 & 3 & 0.0119 & 0.0139 & 0.0129 & 0.0154 & 0.0192 & 0.0155 & 0.0147 & 0.0143 & 0.0158 \\
\hline T200-L4-1 & 4 & 0.0126 & 0.0142 & 0.0134 & 0.0145 & 0.0162 & 0.0195 & 0.0151 & 0.0141 & 0.0159 \\
\hline T200-L4-2 & 4 & 0.0129 & 0.0142 & 0.0135 & 0.0139 & 0.0169 & 0.0183 & 0.0161 & 0.0141 & 0.0159 \\
\hline T200-L4-3 & 4 & 0.0128 & 0.0149 & 0.0138 & 0.0137 & 0.0152 & 0.0175 & 0.0173 & 0.0158 & 0.0159 \\
\hline T400-L2-1 & 2 & 0.0107 & 0.0133 & 0.0120 & 0.0141 & 0.0171 & 0.0197 & 0.0161 & 0.0140 & 0.0162 \\
\hline T400-L2-2 & 2 & 0.0109 & 0.0139 & 0.0124 & 0.0138 & 0.0144 & 0.0180 & 0.0195 & 0.0150 & 0.0162 \\
\hline T400-L2-3 & 2 & 0.0109 & 0.0134 & 0.0122 & 0.0160 & 0.0195 & 0.0171 & 0.0143 & 0.0141 & 0.0162 \\
\hline T400-L3-1 & 3 & 0.0120 & 0.0140 & 0.0130 & 0.0165 & 0.0194 & 0.0166 & 0.0149 & 0.0132 & 0.0161 \\
\hline T400-L3-2 & 3 & 0.0119 & 0.0141 & 0.0130 & 0.0135 & 0.0141 & 0.0166 & 0.0195 & 0.0170 & 0.0161 \\
\hline T400-L3-3 & 3 & 0.0121 & 0.0141 & 0.0131 & 0.0141 & 0.0163 & 0.0194 & 0.0166 & 0.0144 & 0.0162 \\
\hline T400-L4-1 & 4 & 0.0127 & 0.0147 & 0.0137 & 0.0156 & 0.0183 & 0.0151 & 0.0166 & 0.0140 & 0.0159 \\
\hline T400-L4-2 & 4 & 0.0129 & 0.0145 & 0.0137 & 0.0149 & 0.0142 & 0.0152 & 0.0193 & 0.0161 & 0.0159 \\
\hline T400-L4-3 & 4 & 0.0128 & 0.0145 & 0.0136 & 0.0142 & 0.0159 & 0.0193 & 0.0155 & 0.0150 & 0.0160 \\
\hline T600-L2-1 & 2 & 0.0114 & 0.0140 & 0.0127 & 0.0174 & 0.0207 & 0.0177 & 0.0152 & 0.0153 & 0.0172 \\
\hline T600-L2-2 & 2 & 0.0110 & 0.0142 & 0.0126 & 0.0154 & 0.0185 & 0.0186 & 0.0182 & 0.0171 & 0.0176 \\
\hline T600-L2-3 & 2 & 0.0121 & 0.0142 & 0.0131 & 0.0142 & 0.0154 & 0.0176 & 0.0190 & 0.0207 & 0.0174 \\
\hline T600-L3-1 & 3 & 0.0128 & 0.0149 & 0.0139 & 0.0151 & 0.0160 & 0.0160 & 0.0186 & 0.0205 & 0.0172 \\
\hline T600-L3-2 & 3 & / & / & / & / & / & / & / & / & / \\
\hline T600-L3-3 & 3 & 0.0128 & 0.0148 & 0.0138 & 0.0177 & 0.0205 & 0.0182 & 0.0156 & 0.0144 & 0.0173 \\
\hline T600-L4-1 & 4 & / & / & / & / & / & / & / & / & / \\
\hline T600-L4-2 & 4 & 0.0136 & 0.0153 & 0.0144 & 0.0152 & 0.0161 & 0.0170 & 0.0203 & 0.0173 & 0.0172 \\
\hline T600-L4-3 & 4 & 0.0137 & 0.0153 & 0.0145 & 0.0161 & 0.0193 & 0.0172 & 0.0169 & 0.0161 & 0.0172 \\
\hline T800-L2-1 & 2 & 0.0114 & 0.0143 & 0.0129 & 0.0169 & 0.0188 & 0.0179 & 0.0176 & 0.0169 & 0.0176 \\
\hline T800-L2-2 & 2 & 0.0114 & 0.0143 & 0.0128 & 0.0158 & 0.0154 & 0.0178 & 0.0208 & 0.0186 & 0.0177 \\
\hline T800-L2-3 & 2 & 0.0113 & 0.0142 & 0.0128 & 0.0155 & 0.0157 & 0.0171 & 0.0194 & 0.0207 & 0.0177 \\
\hline T800-L3-1 & 3 & 0.0129 & 0.0149 & 0.0139 & 0.0175 & 0.0205 & 0.0181 & 0.0163 & 0.0151 & 0.0175 \\
\hline T800-L3-2 & 3 & 0.0126 & 0.0145 & 0.0135 & 0.0155 & 0.0165 & 0.0178 & 0.0194 & 0.0179 & 0.0174 \\
\hline T800-L3-3 & 3 & 0.0128 & 0.0150 & 0.0139 & 0.0151 & 0.0153 & 0.0180 & 0.0205 & 0.0181 & 0.0174 \\
\hline T800-L4-1 & 4 & 0.0137 & 0.0154 & 0.0146 & 0.0154 & 0.0179 & 0.0204 & 0.0171 & 0.0150 & 0.0172 \\
\hline T800-L4-2 & 4 & 0.0137 & 0.0153 & 0.0145 & 0.0175 & 0.0204 & 0.0175 & 0.0159 & 0.0151 & 0.0173 \\
\hline T800-L4-3 & 4 & 0.0137 & 0.0153 & 0.0145 & 0.0186 & 0.0174 & 0.0168 & 0.0164 & 0.0186 & 0.0173 \\
\hline
\end{tabular}

Note: "/"-Unreliable data.
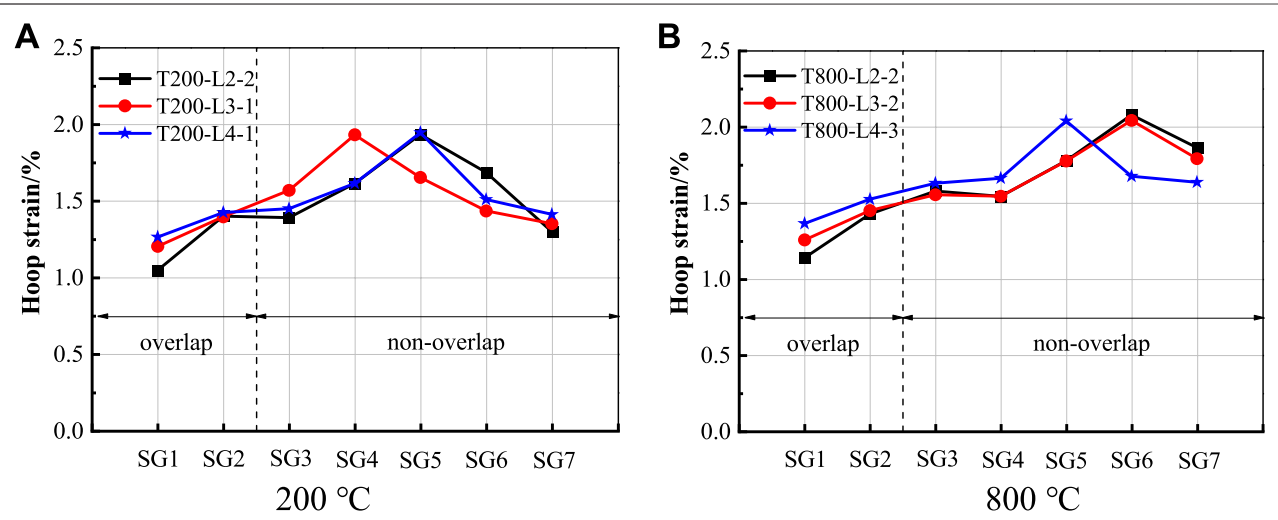

FIGURE 4 | Strain distributions of BFRP-confined concrete cylinders with different damage levels. (A) $200^{\circ} \mathrm{C}$, (B) $800^{\circ} \mathrm{C}$.

core expands, the tension force starts from the inside of the FRP, transmits in the hoop direction, and arrives at the end of the overlapping. After reaching the transition area between the overlapping and the non-overlapping zone, it will cause a sudden change in stiffness. Therefore, in the overlapping zone, the FRP jackets near the end edge exhibit a smaller 
TABLE 4 | Comparisons between the strain measurements recorded in overlapping zone.

\begin{tabular}{lccccc} 
Temperature $\left({ }^{\circ} \mathbf{C}\right)$ & Specimen & Layer & $\frac{\varepsilon_{\text {h.SG1 }}}{\varepsilon_{\text {h.ave }}}$ & $\frac{\varepsilon_{\text {h.SG2 }}}{\varepsilon_{\text {h.,ave }}}$ & $\frac{\mathbf{n}_{\text {non-overlap }}}{\mathbf{n}_{\text {overlap }}}$ \\
\hline 200 & T200-L2-2 & 2 & 0.66 & 0.88 & 0.67 \\
& T200-L3-1 & 3 & 0.76 & 0.88 & 0.75 \\
& T200-L4-1 & 4 & 0.80 & 0.90 & 0.80 \\
\hline \multirow{2}{*}{800} & T800-L2-2 & 2 & 0.64 & 0.81 & 0.67 \\
& T800-L3-2 & 3 & 0.72 & 0.83 & 0.75 \\
& T800-L4-3 & 4 & 0.79 & 0.88 & 0.81 \\
\hline
\end{tabular}

tensile stress, while the FRP jackets far from the end edge exhibit a higher tensile stress.

\section{Strain Distribution in the Non-Overlapping Zone}

In order to further illustrate the influence of historical high temperatures (i.e., different heat-damage levels of concrete) on the strain responses of the BFRP jackets, Figures 5A,B compare the strain distributions in the non-overlapping zones for the specimens confined by two layers and four layers of BFRP jackets, respectively, which are initially exposed to various high temperatures (i.e., $200^{\circ} \mathrm{C}, 400^{\circ} \mathrm{C}, 600^{\circ} \mathrm{C}$, and $800^{\circ} \mathrm{C}$ ). It can be seen that the hoop strain values of the non-overlapping zone are significantly higher than those of the overlapping zone, which are consistent with the observations reported in the literature (Lam and Teng, 2004; Wu and Jiang, 2013; Chen et al., 2013; Pham et al., 2015; Take and Bisby, 2009). Figure 6 shows the strain distributions of four typical specimens under different loading levels. The lateral strains measured in the non-overlapping zone are not uniform, mainly attributed to the inhomogeneity of the concrete that causes the uneven lateral deformations (Lam and Teng, 2004; Take and Bisby, 2009). In addition, when the number of the BFRP jackets is increased from two to four layers, the lateral strain distributions are more uniform. This indicates that the increase of the BFRP layers helps to improve the nonuniformity of the lateral strain distribution. However, the increase in the number of BFRP layers cannot enhance the hoop rupture strain, which means that the confinement efficiency of a single layer of BFRP will not increase with the growth in the number of BFRP jackets.

\section{EFFICIENCY FACTOR OF BFRP IN CONFINED HEAT-DAMAGED CONCRETE}

As stated in the above sections, the efficiency factor of FRP composites is widely used to quantify the confinement and the related pressure provided by the FRP jackets. According to Pessiki et al. (2001), the efficiency factor $k_{\varepsilon}$ consists of two ratios as follows:

$$
k_{\varepsilon}=k_{\varepsilon 1} \cdot k_{\varepsilon 2}=\frac{\varepsilon_{h, \text { ave }}}{\varepsilon_{h, \max }} \cdot \frac{\varepsilon_{h, \max }}{\varepsilon_{f r p}}
$$

where $\varepsilon_{h, a v e}$ is the average hoop strain in the non-overlapping zone, $\varepsilon_{h, \text { max }}$ is the maximum hoop strain of the FRP jackets, $\varepsilon_{f r p}$ is the ultimate strain of the FRP material measured from flat coupon tests.

The first ratio $k_{\varepsilon 1}$ accounts for the effect of a nonuniform strain distribution in the FRP jackets, while the second ratio $k_{\varepsilon 2}$ represents the reduction of FRP strain capacity compared with that obtained by the flat coupon tests. The average values of $k_{\varepsilon 1}$ and $k_{\varepsilon 2}$ for all the specimens tested in the present study are determined as 0.851 and 0.897 , respectively. Moreover, the efficiency factor is 0.763 for the 36 BFRP-confined heatdamaged concrete cylinders. The value is very close to those found from the existing test results reported in the literature (Jian and Ozbakkaloglu, 2015), which is 0.704 for 12 CFRP-confined concrete cylinders and 0.718 for 12 GFRP-confined concrete cylinders.

\section{Effect of Historical High Temperature}

The relationship between the efficiency factor and the historical temperatures is presented in Figure 7. As the historical temperature increases, the efficiency factor grows, and the increasing rates for the specimens with different levels of heat damage after exposure to different temperatures are different. It is
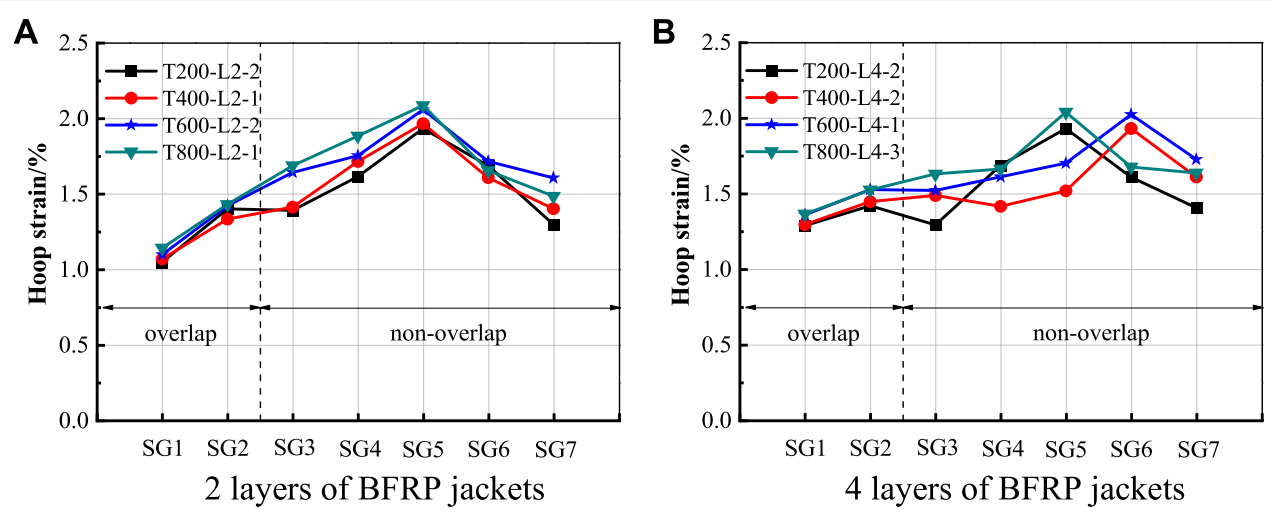

FIGURE 5 | Strain distributions of heat-damaged concrete cylinders confined with different layers of BFRP jackets. (A) Two layers of BFRP jackets, (B) four layers of BFRP jackets. 


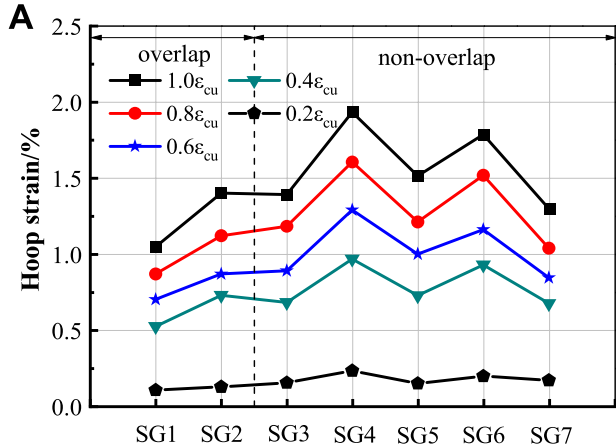

T200-L2-2

C

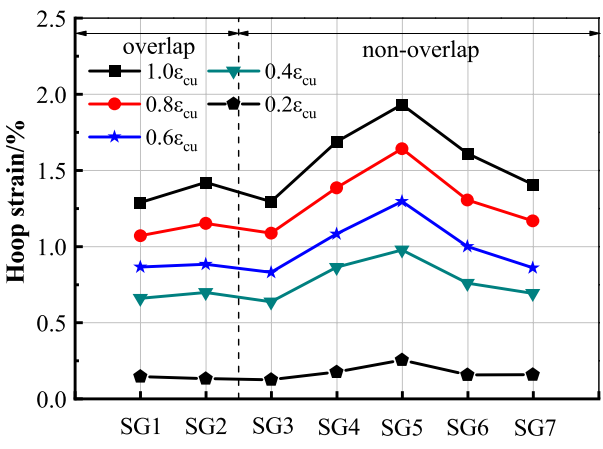

T200-L4-2

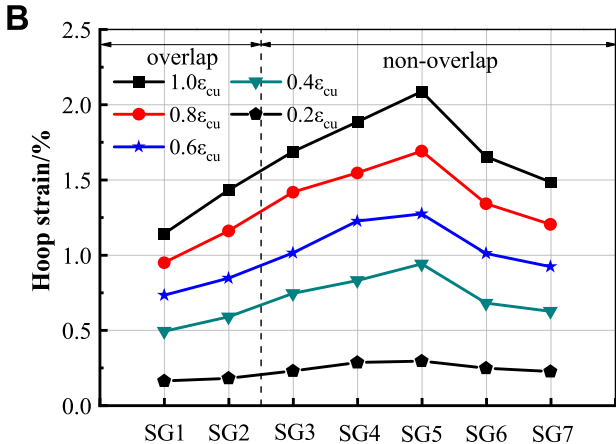

T800-L2-1

D

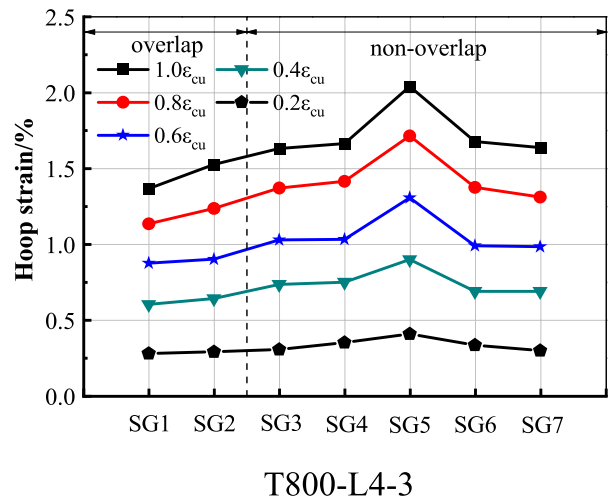

FIGURE 6 | Strain distributions of typical specimens at different load levels. (A) T200-L2-2, (B) T800-L2-1, (C) T200-L4-2, (D) T800-L4-3.

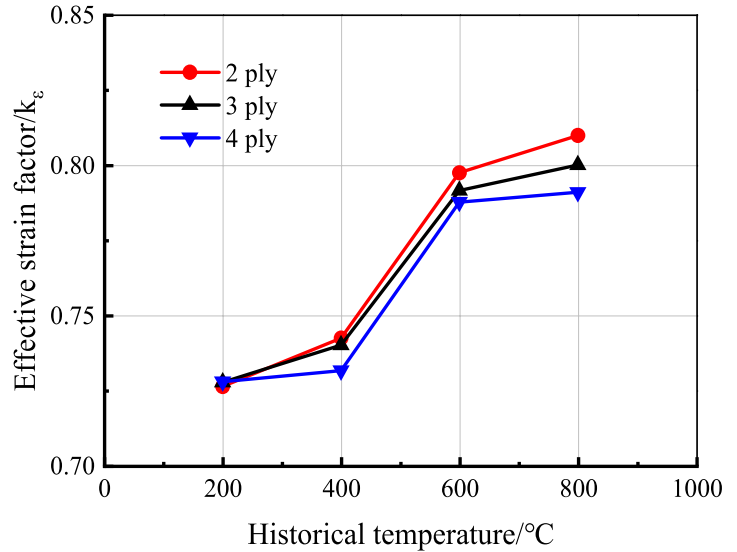

FIGURE 7 | BFRP efficiency factor versus historical high temperature.

apparent that the efficiency factor increases significantly between the exposed temperature from $400^{\circ} \mathrm{C}$ to $600^{\circ} \mathrm{C}$ due to the abrupt deterioration of the compressive strength of concrete (Bisby et al., 2011; Lenwari et al., 2016; Jia et al., 2021).

\section{Effect of Confinement Strength}

Figure 8 illustrates the relationship between the values of the BFRP efficiency factor versus the confinement strengths provided

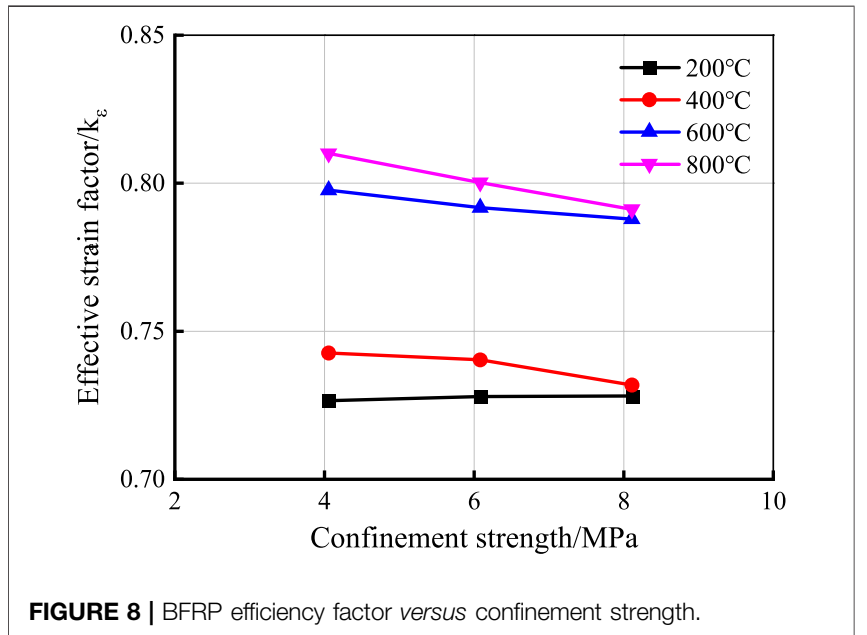

by the BFRP jackets. The values of the BFRP efficiency factor decrease slightly with the increase of the confinement strength under various historical high-temperature conditions. For example, for a confinement strength of about $4.06 \mathrm{MPa}$, the values of the BFRP efficiency factor for the BFRP-confined heat-damaged specimens after exposure to $400^{\circ} \mathrm{C}, 600^{\circ} \mathrm{C}$, and $800^{\circ} \mathrm{C}$ are $0.742,0.798$, and 0.810 , respectively. When the confinement strength is increased to almost $8.12 \mathrm{MPa}$, the 


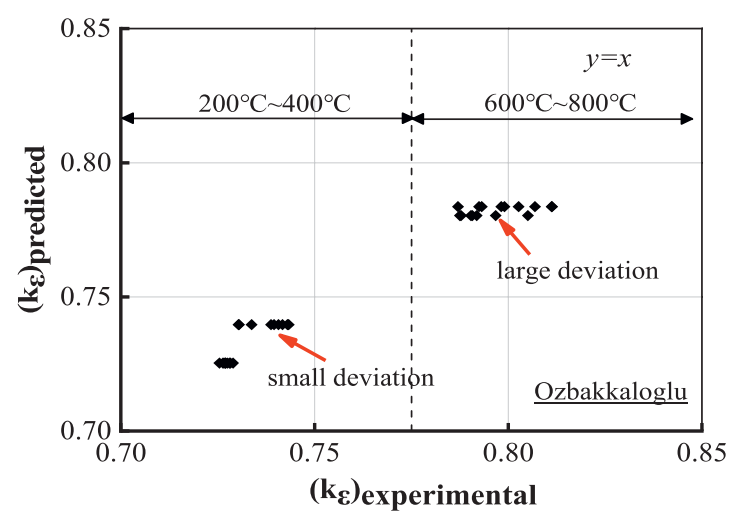

FIGURE 9 | Performance of typical model in predicting BFRP efficiency factor.

efficiency factor values of the corresponding specimens after exposure to $400^{\circ} \mathrm{C}, 600^{\circ} \mathrm{C}$, and $800^{\circ} \mathrm{C}$ decrease by $1.46,1.23$, and $2.34 \%$, respectively. Moreover, as the confinement strength increases, the difference between the values of the efficiency factor for the specimens with different levels of initial heat damage decreases. In other words, under monotonically axial compression, the effect of the confinement strength on the FRP efficiency factor is much smaller than those of compressive strength and ultimate axial strain (Jian and Ozbakkaloglu, 2015). Therefore, the effect of BFRP confinement strength on the efficiency factor is ignored in deducing the design equation of the efficiency factor of BFRP for confined heat-damaged concrete cylinders.

\section{Comparisons and Discussion}

Ozabakkaloglu et al. (2013) collected a large amount of existing test data and proposed a design method of FRP efficiency factor based on the FRP-confined concrete columns tested at ambient temperature. An attempt to use the Ozabakkaloglu et al.'s design method to predict the BFRP efficiency factor for the confined heat-damaged concrete is conducted, and the predicted values of the efficiency factor are shown in Figure 9. The performance of the design method in predicting the efficiency factor of BFRP for the confined heat-damaged concrete columns is evaluated using statistical indicators including the mean squared error (MSE) and the average absolute error (AAE), as described in the following equations:

$$
\begin{gathered}
M S E=\frac{1}{N} \sum_{i=1}^{N}\left(\frac{\operatorname{Pre}_{i}-\operatorname{Exp}_{i}}{E x p_{i}}\right)^{2} \\
A A E=\frac{\sum_{i=1}^{N}\left|\frac{P r e_{i}-E x p_{i}}{E x p_{i}}\right|}{N}
\end{gathered}
$$

where $N$ is the total number of the data points, and $\operatorname{Pre}_{i}$ and $E x p_{i}$ are the prediction and the test result of the $i$ th specimen, respectively.

It can be observed that the method by Ozabakkaloglu et al. (2013) is not capable of predicting the experimental results accurately. When the historical high temperature increases from $200^{\circ} \mathrm{C}$ to $400^{\circ} \mathrm{C}$, the predicted values of the efficiency factor agree reasonably well with the test results, which further verify the applicability of the design method for the FRP-confined concrete columns under ambient temperature conditions. However, when the historical high temperature further increases to $600^{\circ} \mathrm{C}$ or $800^{\circ} \mathrm{C}$, almost all the test data points are lower than the line of equality (solid line in Figure 9), indicating that the method by Ozabakkaloglu et al. (2013) underestimates the efficiency of the BFRP jackets for confining the heat-damaged concrete. Therefore, a new and more accurate design equation is needed to describe the efficiency of BFRP in practical design of BFRP-confined heat-damaged concrete columns, especially for these columns after experiencing moderate or severe heat- or fireinduced damage.

\section{New Design Method for BFRP Efficiency Factor}

As stated in the above sections, the efficiency factor of BFRP jackets used for the confinement of heat-damaged concrete columns relies on the initial concrete damage level. Therefore, a regression curve between the detailed test values of the BFRP efficiency factor versus the historical high temperatures is proposed as follows to describe the effect of historical high temperature:

$$
k_{\varepsilon T}=0.0137\left(\frac{T}{100}\right)+0.6962
$$

The accuracy of the proposed design method is described in Figure 10. It is seen that the BFRP efficiency factor increases almost linearly with the historical high temperature, and the value of $R^{2}$ between the regression curve and the test results is 0.8815 , indicating that there is a good agreement between the test results and the model predictions. It should be noted that the design equation (i.e., Eq. 6) is only described as a function of historical high temperature (i.e., the initial heat damage of concrete), so it has only considered the effect of initial heat damage on the efficiency factor of BFRP jackets for confining heat-damaged concrete. The detailed value of $k_{\varepsilon}$ can be determined by

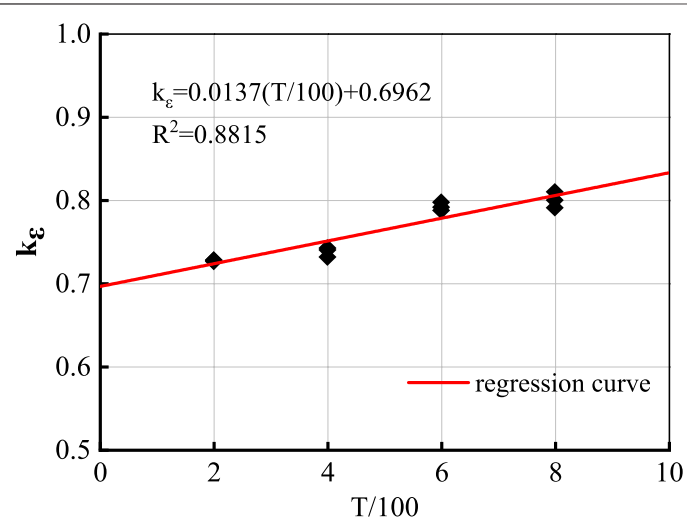

FIGURE 10 | Regression curve of the efficiency factor. $K_{\varepsilon} T$ 
multiplying $k_{\varepsilon T}$ (calculated by Eq. 6) by the corresponding value determined by the exiting design method of the efficiency factor proposed at ambient temperature $\left(k_{\varepsilon 0}\right)$ in the literature [such as those provided in the Refs (Lam and Teng, 2004; Chen et al., 2013; Wu and Jiang, 2013; Jian and Ozbakkaloglu, 2015; Pham et al., 2015)]. That is, the efficiency factor $k_{\varepsilon}=k_{\varepsilon T} \times k_{\varepsilon 0}$.

\section{CONCLUSION}

A series of compressive tests were conducted on BFRP-confined heat-damaged concrete columns. The design parameters included the historical high temperature that was used to produce the initial concrete damage and the number of BFRP jacket layers. The hoop strain responses of the BFRP-confined heat-damaged concrete columns were sufficiently monitored and examined during the loading process. Based on the test results reported in this study, the following conclusions can be drawn.

a. The failure mode of all the BFRP-confined heat-damaged concrete columns was caused by the rupture of BFRP jackets in the non-overlapping zone at around the midheight of each specimen.

b. The hoop strain distribution is not uniform. That is, in the overlapping zone, the measured strain values increase with the distance from the end edge of the FRP jackets. In the nonoverlapping zone, the measured strain values are significantly larger than those of the overlapping zone.

c. The values of the BFRP efficiency factor increase with the increase of the historical high temperature. In particular, when the heat-damaged concrete cylinders confined with two layers of BFRP jackets, the efficiency factors of BFRP are $0.726,0.742$, 0.798 , and 0.810 for the heat-damaged concrete columns after exposure to $200^{\circ} \mathrm{C}, 400^{\circ} \mathrm{C}, 600^{\circ} \mathrm{C}$, and $800^{\circ} \mathrm{C}$, respectively. Therefore, BFRP jackets exhibit better confinement efficiency when the heat damage level of concrete is more significant.

d. The efficiency factor of BFRP decreases slightly as the confinement strength increases. As the confinement strength increases from $4.06-8.12 \mathrm{MPa}$, the efficiency factors of BFRP for the heat-damaged concrete after exposure to high temperatures of $400^{\circ} \mathrm{C}, 600^{\circ} \mathrm{C}$, and $800^{\circ} \mathrm{C}$

\section{REFERENCES}

ACI (2008). 440.2R-08, Guide for the Design and Construction of Externally Bonded FRP Systems for Strengthening concrete Structures. Farmington Hills, USA.

Al-Kamaki, Y. S. S., Al-Mahaidi, R., and Bennetts, I. (2015). Experimental and Numerical Study of the Behaviour of Heat-Damaged RC Circular Columns Confined with CFRP Fabric. Compos. Struct. 133, 679-690. doi:10.1016/ j.compstruct.2015.07.116

ASTM (2017). ASTM D3039, Standard Test Method for Tensile Properties of Polymer Matrix Composite Materials. West Conshohocken, USA: ASTM International.

Bai, Y.-L., Dai, J.-G., and Teng, J.-G. (2017). Monotonic Stress-Strain Behavior of Steel Rebars Embedded in FRP-Confined Concrete Including Buckling. J. Compos. Constr. 21 (5), 04017043. doi:10.1061/(asce)cc.1943-5614.0000823 decrease by $1.46,1.23$, and $2.34 \%$, respectively. The influence of confinement strength on the efficiency factor is much smaller than that of the historical high temperature.

e. The existing design method of FRP efficiency factor cannot accurately predict the test results. Therefore, a new and more accurate design equation is proposed to describe the BFRP efficiency factor in BFRP-confined heat-damaged concrete, which can be combined with the existing design method of the efficiency factor proposed at ambient temperature to achieve an accurate prediction of the BFRP efficiency for confining heat-damaged concrete.

\section{DATA AVAILABILITY STATEMENT}

The original contributions presented in the study are included in the article/supplementary material; further inquiries can be directed to the corresponding authors.

\section{AUTHOR CONTRIBUTIONS}

$\mathrm{BD}$ : test design, $\mathrm{L}-\mathrm{JO}$ and $\mathrm{X}-\mathrm{XW}$ : test design and test data analysis, W-YG: establishing the model.

\section{FUNDING}

The authors are grateful for the financial supports provided by the National Natural Science Foundation of China (Nos: 51978398 and 51708349), the Natural Science Foundation of Shanghai (No. 19ZR1426200), the Natural Science Foundation of Zhejiang (No. LY20E080017) and the Project of Wenzhou Science and Technology Bureau (No. 20180028).

\section{ACKNOWLEDGMENTS}

The authors are also grateful to Prof. Jiang-Tao Yu of Tongji University and Prof. Yu-Lei Bai of Beijing University of Technology for their valuable advices on this research.

Bai, Y.-L., Yan, Z.-W., Ozbakkaloglu, T., Gao, W.-Y., and Zeng, J.-J. (2021). Mechanical Behavior of Large-Rupture-Strain (LRS) Polyethylene Naphthalene Fiber Bundles at Different Strain Rates and Temperatures. Constr. Build. Mater. 297, 123786. doi:10.1016/ j.conbuildmat.2021.123786

Berthet, J. F., Ferrier, E., and Hamelin, P. (2005). Compressive Behavior of concrete Externally Confined by Composite Jackets. Part A: Experimental Study. Constr. Build. Mater. 19, 223-232. doi:10.1016/ j.conbuildmat.2004.05.012

Bisby, L. A., Chen, J. F., Li, S. Q., Stratford, T. J., Cueva, N., and Crossling, K. (2011). Strengthening Fire-Damaged concrete by Confinement with Fibre-Reinforced Polymer Wraps. Eng. Struct. 33 (12), 3381-3391. doi:10.1016/j.engstruct.2011.07.002

Chen, J. F., Li, S. Q., and Bisby, L. A. (2013). Factors Affecting the Ultimate Condition of FRP-Wrapped concrete Columns. J. Compos. Constr. 17 (1), 67-78. doi:10.1061/(asce)cc.1943-5614.0000314 
Dai, J.-G., Bai, Y.-L., and Teng, J. G. (2011). Behavior and Modeling of concrete Confined with FRP Composites of Large Deformability. J. Compos. Constr. 15 (6), 963-973. doi:10.1061/(asce)cc.1943-5614.0000230

De Luca, A., Matta, F., and Nanni, A. (2010). Behavior of Full-Scale Glass FiberReinforced Polymer Reinforced concrete Columns under Axial Load. ACI Struct. J. 107 (5), 589-596. doi:10.14359/51663912

Gao, W.-Y., Dai, J.-G., and Teng, J.-G. (2017). Fire Resistance of RC Beams under Design Fire Exposure. Mag. Concrete Res. 69 (8), 402-423. doi:10.1680/ jmacr.15.00329

Gao, W.-Y., Dai, J.-G., and Teng, J. G. (2016). Fire Resistance Design of Unprotected FRP-Strengthened RC Beams. Mater. Struct. 49 (12), 5357-5371. doi:10.1617/s11527-016-0865-x

Gao, W. Y., Dai, J.-G., Teng, J. G., and Chen, G. M. (2015). Simple Method for Predicting Temperatures in Insulated, FRP-Strengthened RC Members Exposed to a Standard Fire. J. Compos. Constr. 19 (6), 04015013. doi:10.1061/(asce)cc.1943-5614.0000566

Gao, W. Y., Dai, J.-G., Teng, J. G., and Chen, G. M. (2013). Finite Element Modeling of Reinforced concrete Beams Exposed to Fire. Eng. Struct. 52, 488-501. doi:10.1016/j.engstruct.2013.03.017

Gao, W. Y., Dai, J.-G., and Teng, J. G. (2018). Three-level Fire Resistance Design of FRP-Strengthened RC Beams. J. Compos. Constr. 22 (3), 05018001. doi:10.1061/ (asce)cc.1943-5614.0000840

Gao, W. Y., Dai, J. G., and Teng, J. G. (2014). Simple Method for Predicting Temperatures in Reinforced concrete Beams Exposed to a Standard Fire. Adv. Struct. Eng. 17 (4), 573-589. doi:10.1260/1369-4332.17.4.573

GB (2006). GB 50367, Design Code for Strengthening concrete Structure. China: Ministry of Construction issued National Standards.

Guo, Y.-C., Gao, W.-Y., Zeng, J.-J., Duan, Z.-J., Ni, X.-Y., and Peng, K.-D. (2019). Compressive Behavior of FRP Ring-Confined concrete in Circular Columns: Effects of Specimen Size and a New Design-Oriented StressStrain Model. Constr. Build. Mater. 201, 350-368. doi:10.1016/ j.conbuildmat.2018.12.183

Ilki, A., Peker, O., Karamuk, E., Demir, C., and Kumbasar, N. (2008). FRP Retrofit of Low and Medium Strength Circular and Rectangular Reinforced concrete Columns. J. Mater. Civ. Eng. 20 (2), 169-188. doi:10.1061/(asce)08991561(2008)20:2(169)

Jia, D.-G., Gao, W.-Y., Duan, D.-X., Yang, J., and Dai, J.-G. (2021). Full-range Behavior of FRP-To-concrete Bonded Joints Subjected to Combined Effects of Loading and Temperature Variation. Eng. Fracture Mech. 254, 107928. doi:10.1016/j.engfracmech.2021.107928

Jian, C. L., and Ozbakkaloglu, T. (2015). Hoop Strains in FRP-Confined concrete Columns: Experimental Observations. Mater. Struct. 48 (9), 2839-2854. doi:10.1617/s11527-014-0358-8

Jiang, T., and Teng, J. G. (2007). Analysis-oriented Stress-Strain Models for FRPConfined concrete. Eng. Struct. 29, 2968-2986. doi:10.1016/ j.engstruct.2007.01.010

Jiang, T., and Teng, J. G. (2013). Behavior and Design of Slender FRP-Confined Circular RC Columns. J. Compos. Constr. 17 (4), 443-453. doi:10.1061/(asce) cc. $1943-5614.0000333$

Lam, L., Teng, J. G., Cheung, C. H., and Xiao, Y. (2006). FRP-confined concrete under Axial Cyclic Compression. Cem. Concr. Compos. 28, 949-958. doi:10.1016/j.cemconcomp.2006.07.007

Lam, L., and Teng, J. G. (2004). Ultimate Condition of Fiber Reinforced PolymerConfined concrete. J. Compos. Constr. 8 (6), 539-548. doi:10.1061/(asce)10900268(2004)8:6(539)

Lenwari, A., Rungamornrat, J., and Woonprasert, S. (2016). Axial Compression Behavior of Fire-Damaged concrete Cylinders Confined with CFRP Sheets. J. Compos. Constr. 20 (5), 04016027. doi:10.1061/ (asce)cc.1943-5614.0000683

Lim, J. C., and Ozbakkaloglu, T. (2014). Confinement Model for FRP-Confined High-Strength concrete. J. Compos. Constr. 17 (5), 1-19. doi:10.1061/(asce) cc.1943-5614.0000376

Lin, G., and Teng, J. G. (2020). Advanced Stress-Strain Model for FRP-Confined concrete in Square Columns. Compos. B Eng. 197, 108149. doi:10.1016/ j.compositesb.2020.108149

Lin, G., and Teng, J. G. (2017). Three-dimensional Finite-Element Analysis of FRPConfined Circular concrete Columns under Eccentric Loading. J. Compos. Constr. 21 (4), 04017003. doi:10.1061/(asce)cc.1943-5614.0000772
Ouyang, L.-J., Chai, M.-X., Song, J., Hu, L.-L., and Gao, W.-Y. (2021). Repair of Thermally Damaged concrete Cylinders with basalt Fiber-Reinforced Polymer Jackets. J. Build. Eng. 44, 102673. doi:10.1016/j.jobe.2021.102673

Ouyang, L. J., Gao, W. Y., Zhen, B., and Lu, Z. D. (2017). Seismic Retrofit of Square Reinforced concrete Columns Using basalt and Carbon Fiber-Reinforced Polymer Sheets: A Comparative Study. Compos. Struct. 162, 297-307. doi:10.1016/j.compstruct.2016.12.016

Ozbakkaloglu, T., Lim, J. C., and Vincent, T. (2013). FRP-confined concrete in Circular Sections: Review and Assessment of Stress-Strain Models. Eng. Struct. 49 (2), 1068-1088. doi:10.1016/j.engstruct.2012.06.010

Pessiki, S., Harries, K. A., Kestner, J. T., Sause, R., and Ricles, J. M. (2001). Axial Behavior of Reinforced concrete Columns Confined with FRP Jackets. J. Compos. Constr. 5 (4), 237-245. doi:10.1061/(asce)1090-0268(2001)5:4(237)

Pham, T. M., Hadi, M. N. S., and Tran, T. M. (2015). Maximum Usable Strain of FRP-Confined concrete. Constr. Build. Mater. 83, 119-127. doi:10.1016/ j.conbuildmat.2015.03.017

Rousakis, T., and Tepfers, R. (2004). Behavior of concrete Confined by High E-Modulus Carbon FRP Sheets Subjected to Monotonic and Cyclic Axial Compressive Load. Nord. Concr. Res. J. 31, 73-82.

Smith, S. T., Kim, S. J., and Zhang, H. (2010). Behavior and Effectiveness of FRP Wrap in the Confinement of Large Concrete Cylinders. J. Compos. Constr. 14 (5), 573-582. doi:10.1061/(asce)cc.1943-5614.0000119

Song, J., Gao, W.-Y., Ouyang, L.-J., Zeng, J.-J., Yang, J., and Liu, W.-D. (2021). Compressive Behavior of Heat-Damaged Square concrete Prisms Confined with basalt Fiber-Reinforced Polymer Jackets. Eng. Struct. 242, 112504. doi:10.1016/j.engstruct.2021.112504

Take, W. A., and Bisby, L. A. (2009). Strain Localizations in FRP-Confine concrete: New Insights. Proc. Inst. Civil Eng. Struct. Build. 162 (5), 301-309. doi:10.1680/ stbu.2009.162.5.301

Wang, D., Wang, Z., Smith, S. T., and Yu, T. (2017). Seismic Performance of CFRPConfined Circular High-Strength concrete Columns with High Axial Compression Ratio. Constr. Build. Mater. 134, 91-103. doi:10.1016/ j.conbuildmat.2016.12.108

Wang, L.-M., and Wu, Y.-F. (2008). Effect of Corner Radius on the Performance of CFRP-Confined Square concrete Columns: Test. Eng. Struct. 30, 493-505. doi:10.1016/j.engstruct.2007.04.016

Wu, Y.-F., and Jiang, J.-F. (2013). Effective Strain of FRP for Confined Circular concrete Columns. Compos. Struct. 95, 479-491. doi:10.1016/ j.compstruct.2012.08.021

Xiao, Y., and Wu, H. (2000). Compressive Behavior of concrete Confined by Carbon Fiber Composite Jackets. J. Mater. Civ. Eng. 12 (2), 139-146. doi:10.1061/(asce)0899-1561(2000)12:2(139)

Yan, Z.-W., Bai, Y.-L., Ozbakkaloglu, T., Gao, W.-Y., and Zeng, J.-J. (2021). Ratedependent Compressive Behavior of concrete Confined with Large-Rupture-Strain (LRS) FRP. Compos. Struct. 272, 114199. doi:10.1016/j.compstruct.2021.114199

Yang, J., Peng, G.-F., Zhao, J., and Shui, G.-S. (2019). On the Explosive Spalling Behavior of Ultra-high Performance concrete with and without Coarse Aggregate Exposed to High Temperature. Constr. Build. Mater. 226, 932-944. doi:10.1016/j.conbuildmat.2019.07.299

Yaqub, M., Bailey, C. G., and Nedwell, P. (2011). Axial Capacity of post-heated Square Columns Wrapped with FRP Composites. Cem. Concr. Compos. 33, 694-701. doi:10.1016/j.cemconcomp.2011.03.011

Yaqub, M., Bailey, C. G., Nedwell, P., Khan, Q. U. Z., and Javed, I. (2013). Strength and Stiffness of post-heated Columns Repaired with Ferrocement and Fibre Reinforced Polymer Jackets. Compos. Part B Eng. 44, 200-211. doi:10.1016/ j.compositesb.2012.05.041

Yaqub, M., and Bailey, C. G. (2011). Repair of Fire Damaged Circular Reinforced concrete Columns with FRP Composites. Constr. Build. Mater. 25 (1), 359-370. doi:10.1016/j.conbuildmat.2010.06.017

Yu, T., Teng, J. G., Wong, Y. L., and Dong, S. L. (2010). Finite Element Modeling of Confined concrete-I: Drucker-Prager Type Plasticity Model. Eng. Struct. 32 (3), 665-679. doi:10.1016/j.engstruct.2009.11.014

Yu, T., Teng, J. G., Wong, Y. L., and Dong, S. L. (2010). Finite Element Modeling of Confined concrete-II: Plastic-Damage Model. Eng. Struct. 32 (3), 680-691. doi:10.1016/j.engstruct.2009.11.013

Zeng, J.-J., Chen, S.-P., Zhuge, Y., Gao, W.-Y., Duan, Z.-J., and Guo, Y.-C. (2021). Threedimensional Finite Element Modeling and Theoretical Analysis of concrete Confined with FRP Rings. Eng. Struct. 234, 111966. doi:10.1016/j.engstruct.2021.111966 
Zeng, J.-J., Duan, Z.-J., Gao, W.-Y., Bai, Y.-L., and Ouyang, L.-J. (2020). Compressive Behavior of FRP-Wrapped Seawater Sea-Sand concrete with a Square Cross-Section. Constr. Build. Mater. 262, 120881. doi:10.1016/j.conbuildmat.2020.120881

Zeng, J.-J., Gao, W.-Y., Duan, Z.-J., Bai, Y.-L., Guo, Y.-C., and Ouyang, L.-J. (2020). Axial Compressive Behavior of Polyethylene Terephthalate/carbon FRPConfined Seawater Sea-Sand concrete in Circular Columns. Constr. Build. Mater. 234, 117383. doi:10.1016/j.conbuildmat.2019.117383

Zeng, J.-J., Guo, Y.-C., Gao, W.-Y., Chen, W.-P., and Li, L.-J. (2018). Stress-strain Behavior of concrete in Circular concrete Columns Partially Wrapped with FRP Strips. Compos. Struct. 200, 810-828. doi:10.1016/ j.compstruct.2018.05.001

Zeng, J.-J., Guo, Y.-C., Gao, W.-Y., Li, J.-Z., and Xie, J.-H. (2017). Behavior of Partially and Fully FRP-Confined Circularized Square Columns under Axial Compression. Constr. Build. Mater. 152, 319-332. doi:10.1016/j.conbuildmat.2017.06.152

Zeng, J.-J., Ye, Y.-Y., Gao, W.-Y., Smith, S. T., and Guo, Y.-C. (2020). Stress-strain Behavior of Polyethylene Terephthalate Fiber-Reinforced Polymer-Confined normal-, High- and Ultra High-Strength concrete. J. Build. Eng. 30, 101243. doi:10.1016/j.jobe.2020.101243

Zhou, Y., Liu, X., Xing, F., Cui, H., and Sui, L. (2016). Axial Compressive Behavior of FRP-Confined Lightweight Aggregate concrete: an Experimental Study and
Stress-Strain Relation Model. Constr. Build. Mater. 119, 1-15. doi:10.1016/ j.conbuildmat.2016.02.180

Conflict of Interest: The authors declare that the research was conducted in the absence of any commercial or financial relationships that could be construed as a potential conflict of interest.

Publisher's Note: All claims expressed in this article are solely those of the authors and do not necessarily represent those of their affiliated organizations, or those of the publisher, the editors and the reviewers. Any product that may be evaluated in this article, or claim that may be made by its manufacturer, is not guaranteed or endorsed by the publisher.

Copyright (c) 2021 Ouyang, Wei, Ding and Gao. This is an open-access article distributed under the terms of the Creative Commons Attribution License (CC BY). The use, distribution or reproduction in other forums is permitted, provided the original author(s) and the copyright owner(s) are credited and that the original publication in this journal is cited, in accordance with accepted academic practice. No use, distribution or reproduction is permitted which does not comply with these terms. 